\title{
Inference and Rational Commitment
}

\author{
JAMES TRAFFORD \\ University for the Creative Arts at Epsom, Ashley Road, Epsom, Surrey, KT18 5BE, Great Britain \\ jtrafford2@ucreative.ac.uk \\ ORIGINAL SCIENTIFIC ARTICLE / RECEIVED: 14-09-12 ACCEPTED: 30-3-13
}

\begin{abstract}
What is it that explains the rationality of transitions in thought? It is natural to think that any such explanation will need to advert to at least two interrelated issues. The first has to do with what is constitutive of the validity of a transition, and the second with our actual practice of making inferential transitions. Many accounts attempt to deal with both issues simultaneously by showing how it is that a thinker, competent with a logical expression $\mathrm{N}$, grasps the content of $\mathrm{N}$ in such a way as to make their inferential practices with $\mathrm{N}$ rational. Advocates of the conceptualist approach to rationality, such as Christopher Peacocke, attempt to account for this relationship by grounding rationality in concept possession. This paper argues against this account, because (a) it cannot provide an appropriate way of distinguishing true and false normative commitments; (b) typing a token cognitive state as a propositional attitude does not depend upon any specific set of conditions that thinkers must instantiate as a matter of metaphysical necessity. In response, I briefly offer suggestions towards an alternative, and psychologically tractable, account of rational commitment by resisting the tendency to run-together the two issues.
\end{abstract}

KEY WORDS: Inference, rationality, Peacocke, thought.

\section{Grasp of content}

What is it that explains the rationality of transitions in thought? It is natural to think that any such explanation will need to advert to at least two inter-related issues. The first has to do with what is constitutive of the validity of a transition, and is closely connected to how logical contents are attached to logical expressions in the correct way. The second has to do with our actual practice of making inferential transitions, and is connected with how thinkers grasp logical contents.

The kind of story that is often given is one in which both issues are dealt with by showing how it is that a thinker, competent with a logical 
expression $\mathrm{N}$, grasps the content of $\mathrm{N}$ in such a way as to make their inferential practices with $\mathrm{N}$ rational. Such an account will, presumably, hope to say how token mental states can have the right sort of content, as a matter of metaphysical necessity:

(Relation): It is constitutive of a thinker T's competence with a logical expression $\mathrm{N}$ for $\mathrm{T}$ to stand in relation $\mathrm{R}$ to $\mathrm{N}$

( $R$ is a cognitive state $T$ is in when they grasp the content $N$ ).

Here is a first blush attempt:

(Relation $)_{1}$ Let $\mathrm{R}$ be knowing the logical rules for N; It is constitutive of a thinker T's competence with a logical expression $\mathrm{N}$ for $\mathrm{T}$ to stand in relation $\mathrm{R}$ to $\mathrm{N}$.

There are good reasons to think that this is too strong. It is common to assume a semantic theory according to which the content of a logical expression is as follows. Logical content is the contribution that a logical expression makes to the truth-conditions of propositions in which it occurs, where those truth-conditions are constraints on the way that the world must be if that proposition is true (or false). Take the (fairly simple) rules for conjunction:

$(\mathrm{C}):((\mathrm{a} \wedge \mathrm{b})$ is true iff $(\mathrm{a})$ is true, and (b) is true)

Here, the occurrence of $\wedge$ in a proposition expressed by the sentence "a and b" may be thought to contribute to the truth-conditions of $(a \wedge b)$ its Boolean function (as captured in the standard truth-table). So, $\wedge$ has the semantic function of conjunction because its content requires the sentence to conform to the logical properties of conjunction.

Thus, $\left(\right.$ Relation $\left._{1}\right)$ does fairly well with respect to the first issue, but it is a further question, however, how a token mental state comes to have these specific logical properties as its content, and thus play a role in intentional psychology, since, alone, they seem prima facie inadequate to type token mental states. The problem is one of determining how it is possible for mental transitions to come into contact with those, abstract contents. This is somewhat tricky because, for example, it does not seem possible even in relatively simple cases to determine every instance of the truth-preserving schema for " $\mathrm{a} \wedge \mathrm{b} \mid-\mathrm{b}$ " in advance of being able to know whether or not it is valid. Consider that, in order to entertain a proposition involving conjunction $(\mathrm{P})$, a thinker must first grasp the content of conjunction. But, if grasping the content of conjunction consists in knowing every instance of $(\mathrm{C})$, then thinkers must have propositional knowledge of the truth-conditions of $(\mathrm{P})$ prior to entertaining $(\mathrm{P})$. Put this way, famously, grasping $\wedge$ involves conjunction itself: for, how, otherwise, could 
it be the case that, in order to grasp $\wedge$, a thinker must antecedently accept (C) $?^{1}$

There is also a difficulty in explaining how thinkers (e.g. children) can make inferences involving $\wedge$ without an ability to state principles such as $(C)$, since they would be disqualified from grasping the relevant logical content. Any such account would appear to be too conceptually demanding, since many people cannot state the relevant rules, whilst, (at least seeming to be) making logical inferences. ${ }^{2}$

What is crucial is that explaining the rationality of a transition makes the right kind of contact between the abstract formulation of truth-conditions and token mental states. One important response to these issues is Christopher Peacocke's (1992b; 1999) account, which says that a thinker's grasp of the concepts involved in transitions involves assent to a set of dispositions or inferential abilities to make the correct inferences and judgments. This allows for a potential definition of (Relation) as follows:

$\left(\right.$ Relation $_{2}$ ) Let $\mathrm{R}$ be a disposition to infer in accord with the valid inferences for N; It is constitutive of a thinker T's competence with a logical expression $\mathrm{N}$ for $\mathrm{T}$ to stand in relation $\mathrm{R}$ to $\mathrm{N}$.

In turning to concept possession, the suggestion is that assent to a set of dispositions or inferential abilities to make the correct inferences and judgments is involved in understanding the meanings of those concepts. In rough, the correct inferences for $\mathrm{N}$ form its "possession conditions". These conditions both determine the content of $\mathrm{N}$, and are required to be instantiated by a thinker possessing a concept $\mathrm{N}$ in order to type a specific cognitive state as a specific propositional attitude involving N, thus avoiding the issues with $\left(\right.$ Relation $\left._{1}\right)$ raised above.

This is the position I discuss in this paper, which I briefly outline in $\S 2$. In $\S 3$, I challenge the attempt to ground rationality in concept possession, because the conditions upon concept possession fail to be substantive enough to guarantee normativity, before $(\S 4)$ saying that the account is empirically intractable since typing a token cognitive state as a propositional attitude does not depend upon any specific set of conditions that thinkers must instantiate as a matter of metaphysical necessity. In §5 I say that the account cannot find support either in externalism, or in Peacocke's account of implicit conception. Finally, in $\S 6$, I discuss what op-

\footnotetext{
${ }^{1}$ See Kalderon (2001): one "[...] cannot coherently claim that a speaker could come to entertain the content of existential quantification by knowing the standard explanation since the standard explanation presupposes the antecedent intelligibility of existential quantification."

${ }^{2}$ For discussion, see Boghossian (2001: 638), Harman (1986: 17-19).
} 
tions are available for an account of rational commitment, offering brief suggestions that refuse the tendency to run together the two issues (raised above), and draw upon recent work in cognitive psychology to offer some support.

\section{From possession conditions to normativity}

On Peacocke's (1992b) account, for a thinker to possess a concept, they must find certain privileged inferences "primitively compelling". An inference is primitively compelling if a thinker finds it compelling, it is underived from other principles, and its correctness is not answerable to anything else for possession of a certain concept. Furthermore, this set of inferences constituting a concept's possession conditions also individuate that concept so two concepts are distinct if their possession conditions differ.

So, according to Peacocke, a concept such as "and" is individuated by certain possession conditions that a thinker must satisfy in order to possess that concept. In the case of "and", a thinker must be primitively compelled to infer in accord with the natural deduction rules for conjunction:

(Conjunction $\left._{\text {INTRO }}\right): \mathrm{a}, \mathrm{b} / \mathrm{a} \wedge \mathrm{b}$

$\left(\right.$ Conjunction $\left._{\text {ELIM }}\right): \mathrm{a} \wedge \mathrm{b} / \mathrm{a}, \mathrm{b}$

Effectively, a thinker must be disposed to accept the validity of these specific rules in order to possess that concept, and so this can be put in terms of a fairly widely held supervenience thesis:

(Supervenience) Where two thinkers A and B have attitudes involving concepts $\mathrm{C}_{\mathrm{a}}$ and $\mathrm{C}_{\mathrm{b}}$, and they have the same set of dispositions to make inferences and judgments involving $\mathrm{C}_{\mathrm{a}}$ and $\mathrm{C}_{\mathrm{b}}$, then $\mathrm{A}$ and $\mathrm{B}$ possess the same concept $C$.

Rationality is built in to the account in two ways. First, in order for a thinker to make judgments involving a content, they are obliged to infer in certain ways, because concepts are individuated in terms of their role in judgment. Thus, the inferences mentioned in a concept's possession conditions are not supposed to be merely descriptive; rather, they are rationally required of a thinker if they are to make any judgments involving that concept at all:

If rationality permits a thinker to withhold judgment on a content containing a given concept, in specified circumstances, while continuing to possess that concept, then it is possible for a thinker to withhold such judgment while possessing the concept. It follows that willingness to make such a judgment 
cannot be part of the possession condition for the concept in question. (Peacocke 1999: 19)

Second, Peacocke argues that the possession conditions for a concept also determine the semantic value for that concept so as to ensure that the inferential transitions involving that concept (where possessed) will turn out to be truth-preserving: ${ }^{3}$

Outright acceptance of a transition would not be rational unless it were obviously truth-preserving. All the transitions outright acceptance of which are mentioned in the possession condition for a concept must be always truthpreserving, that is, truth-preserving whatever instance is in question. (Peacocke 2005: 171)

Hence, rationality is, in effect, written-in to the account from the outset.

\section{Building-in false commitments}

In order for Peacocke's account to provide an extensionally adequate account of the determination of meaning, there must be some constraints on possession conditions because not every set of inferential rules is constitutive of a genuine concept.

This point is well known from Prior's (1961) arguments regarding a (alleged) connective, tonk, which can be introduced with the following rules of inference:

Tonk $_{\text {INTRO: }} \mathrm{a} / \mathrm{a}$ tonk $\mathrm{b}$

Tonk $\mathrm{ELIM}_{\mathrm{M}}$ : a tonk $\mathrm{b} / \mathrm{b}$

Tonk trivializes inferential practice since it allows a thinker to infer arbitrary propositions from any premise. Let us say, then, in keeping with the program of this paper, that the concept "tonk" builds in false normative commitments to its possession conditions. Hence, if we allow that the inference-form alone suffices to determine the concept, then something has gone wrong: the inferential rules effectively fail to determine a thinkable propositional content. It is, therefore, necessary to provide a way of discerning which rules of inference confer genuine meanings on a logical connective.

There are a number of possibilities for restricting conceptual roles available in the literature, but they are, by and large, unsuccessful. For example, one suggestion due to Belnap (1962) is that the rules must give a conservative extension whereby a logical constant introduced into the

\footnotetext{
${ }^{3}$ This is Peacocke's (1992b) "determination theory".
} 
vocabulary should not allow for an inference not involving the new constant to be deducible that was not deducible before the constant was added (Dummett 1973: 454). Tonk clearly fails on this account, but, given however that conservative extension is relative to the underlying logical system, this does little to settle the problem of whether or not inference-rules express a genuine meaning. As Schecter and Enoch (2006) put it:

[...] considerations of conservativeness only apply to a concept given some inferential background; whether a rule is a conservative extension can only be evaluated with respect to some presupposed derivability relation.

There are also occasions where conservative extension fails, such as for second-order logic, which are nonetheless taken to be valid.

Resultantly, according to Peacocke (2004), we should restrict the determination of genuine concepts in accord with truth-preservation:

Even if mere warranted assertibility were the aim of judgment, we would still need to say which sets of rules determine genuine meanings and which do not. Unless this theorist has some new resource for ruling out spurious meanings, he will need to rely on considerations having to do with reference, semantic value and truth; and then his conceptual role theory is no longer pure. (21)

In rough, this constraint may be put as follows:

(TP) A thinker correctly uses a sentence involving a logical term if, of the proposition expressed by that use, it is truth-preserving.

This expresses the idea the semantic values of logical terms are assigned so as to ensure that their conceptual roles are necessarily truth-preserving where those rules determine a genuine meaning. This constraint, as applied to tonk, shows that there is no binary function on truth-values that validates both its introduction and elimination rules, and, hence, there is no coherent semantic value for tonk. The introduction rule requires that "a tonk b" is true when a is true and b is false, but the elimination rule requires that when a is true and b is false, "a tonk b" is false. Hence, there are no coherent semantic assignments of truth-values for tonk since there is no truth-function that makes tonk-inferences truth-preserving. As Peacocke (1992a: 802) puts it, there can be no determinate way the world has to be, if "a tonk b" is to come out true. ${ }^{4}$

${ }^{4}$ For example, Peacocke (1987) argues that: "For each logical concept [...] there are principles containing it such that it is partially constitutive of possessing that concept that the thinker has the primitive impression that those principles hold. Semantic values are assigned to the constants in such a way as to validate these principles. It follows that in these logical cases, the impression that such underived principles hold is sufficient for them to hold." (178) 
However, this puts pressure on the suggestion that the account really does support something like (Relation 2 ), because of Peacocke's (2004) insistence that the account provides an explanation of thinkers' justification in employing the inferential rules encoded by the possession conditions. Upholding $\left(\right.$ Relation $\left._{2}\right)$ requires that, for an inference that is part of the possession conditions for a concept (thus constitutive of the content of that concept), any thinker possessing the concept is justified in employing that inference. ${ }^{5}$ (TP) allows Peacocke to say that justification flows from the guarantee that conceptual roles are constrained so as to guarantee truthpreservation. But, given that "tonk" shows that one cannot be justified in virtue of inferring according to any set of conceptual roles, the justification for employing those rules would now appear to flow from their truthpreservation, in which case it is this, rather than possession conditions, that is primarily accounting for rational commitment. ${ }^{6}$

This latter point is problematic for $\left(\right.$ Relation $\left._{2}\right)$, since, in order to account for the rationality of inferential transitions involving logical terms, it seems that we would require, in addition to (Supervenience), knowledge of the validity of the relevant rules that are supposed to constitute the content of a concept. ${ }^{7}$ In which case, $\left(\right.$ Relation $\left._{2}\right)$ collapses into (Relation $\left.{ }_{1}\right)$.

Let me embellish this point further. Conjunction may look like a rather silly example here, since almost nobody disputes the classical rules. However, consider the following, well known, issue. Let the inferenceform for "true" comprising its possession conditions be defined according to the T-schema:

Truth $_{\text {INTRO: If }} \mathrm{p}$, then $<\mathrm{p}>$ is true

Truth $_{\text {ELIM }}$ : If $<p>$ is true, then $p$

Accepting classical logic and semantic self-sufficiency (together with assumption that propositions are structures of concepts), all of which Peacocke does, entails that the naïve concept of truth similarly has built-in to it false normative commitments. These come to light in the context of the Liar paradox:

(L): This sentence is not true

${ }^{5}$ This latter point is central in Peacocke's "metasemantic" account of apriori justification encapsulated in Peacocke's (2004) "Rationalist Dependence Thesis": "The rational truth-conduciveness of any given transition to which a thinker is entitled is to be philosophically explained in terms of the nature of the intentional contents and states involved in the transition." (52)

${ }^{6}$ Horwich (2005: 5) makes a similar point.

${ }^{7}$ That is, given that we reject reliabilism for justification. For an account of the familiar reasons not to do so, see Bonjour (1985). 
If we say that (L) is true, then things will be as it says, in which case, (L) would be true, but, if (L) is true, then (L) is also not true. If it is not true, then, since it says of itself that it is not true, then it is true. So, if (L) is not true, then (L) is true. The concept "true", defined according to the Tschema, would commit the user to infer contradictions. ${ }^{8}$

Now, consider what we should now say about "true". Given (TP), since the inferential rules for "true" are not truth-preserving, by Peacocke's account, there can be no semantic value that ensures those inferences determine a genuine meaning. That is to say, if we restrict the determination of genuine concepts in the way that Peacocke suggests, then, since there is no semantic value that can make the possession conditions for "true" truth-preserving, we should say that "true" is not a genuine concept (and perhaps expect it to fall by the wayside with "tonk").

But, of course, in many circumstances, we have utterances that involve the expression 'true', and thoughts that seem to involve "true", all of which we normally attribute as having truth-values. In fact, that "true" as used in natural language expressions is meaningful seems to be pretty much a Moorean fact, and, is, at least, not something that Peacocke's system can do without. It seems, then, that, whilst the possession conditions for "true" may be inconsistent, this should not be taken as evidence to think that "true" does not, nonetheless, have determinate content. Why should we not say instead that the semantic value of true fails to satisfy the inference-form that we thought to be constitutive of its meaning, and so the semantic content of "true" is not determinately settled by its possession conditions? As the literature surrounding the Liar makes clear, getting the correct account of "true" is not something that is separable from considerable cognitive and theoretical reflection. ${ }^{9}$ Ergo, possession conditions cannot (alone) ground rationality.

\section{Competence failure}

As further support for this latter suggestion, to wit; the semantic content of logical expressions is not determinately settled by what it takes for thinkers to possess that concept, and so normativity cannot be grounded in

\footnotetext{
${ }^{8}$ For similar presentations of this argument in the context of Tarski's view on inconsistent languages, see Eklund (2002).

${ }^{9}$ See, for example, the theory of truth presented by Kripke (1975). In fact, even if Peacocke were to suggest that a successor concept "true 1 " be introduced in place of "true", this does not seem to do justice to the dialectic here, since we would still end up counting all previous uses of "true" as content-less, and, moreover, it rules out the view that the successor concept is about the same thing.
} 
the latter, consider that Peacocke's account is not empirically tractable to suffice as a general constraint on thinking with a concept.

The inferential rules to which thinkers are disposed in virtue of grasping content are supposedly guaranteed to be correct given that they are truth-preserving, and, in relation to belief-formation, these dispositions are manifested in fixing propositional attitudes relevant to a thinker's judgments. But, it does not seem acceptable to say that in order to grasp a content, every inference of introduction or elimination needs to be manifested in judgments. If that were so, then thinkers grasping a content would not be capable of making errors of judgments, or basic inferential mistakes; if they did, they could not be ascribed a judgment with that content. This seems too inflexible a requirement to deal with the practice of actual thinkers.

One way that the problem might be dealt with is by allowing for performance errors. It may be possible to introduce a fairly standard performance / competence distinction, in which a thinker's actual inferential practices do not tell against their competence, because of various performance errors; interference factors; memory limitations; distractions and so on. ${ }^{10}$ One might appeal, for example, to the idea that there occur cases in which thinkers make mistakes regarding inferences of introduction rules, for example, because those dispositions are masked. ${ }^{11}$ Though, for this to have traction, one has to be careful, since, it is required that whatever is constitutive of content ought to be manifested in a thinker's actual dispositions in order to ascribe the correct content to that thinker. Now, say, for example, that it is allowed that a thinker can be ascribed an attitude with a specific content in terms of a particular competence that thinker possesses, but that this competence is not performed in the thinker's judgments. Then, it becomes tricky to see how a thinker can be attributed with that content rather than some other content that does seem to be performed in their judgments. ${ }^{12}$

Consider, for example, the conjunction fallacy (Kahneman \& Tversky 1982). In such cases, participants routinely and systematically fail to infer in accordance with the conjunction elimination rule; and rather, suggest that the probability of $(A \& B)$ is greater than $(A)$, (i.e. $P(A \& B) \geq P(A)$ ). Whilst many philosophers have discussed the relevance of heuristics and biases literature to performance ability, the relevance to competency is

\footnotetext{
${ }^{10}$ See Chomsky (1965: 3-4).

${ }^{11}$ The general idea might be that the disposition is present, but certain factors prevent its manifestation. For a discussion of masked dispositions, see Lewis (1997).

${ }^{12}$ In essence, this objection to dispositionalism is in Kripke (1982: 30).
} 
not often recognized, for; if the fallacy corresponded to performance error alone, there should be random failures with little correlation, but those failures are systematic and consistent:

If each departure from normative responding represents a momentary processing lapse due to distraction, carelessness, or temporary confusion, then there is no reason to expect covariance among biases across tasks (or covariance among items within tasks, for that matter) because error variances should be uncorrelated. (West \& Stanovich 2000: 646)

It seems, there, that thinkers routinely entertain thoughts even with simple logical contents such as conjunction, whilst nonetheless failing to instantiate the relevant inferential rules. In that case, thinkers may be attributed attitudes involving certain contents whilst not also instantiating the necessary conditions to ensure that their inferential practice can be determinately truth-preserving.

Recall that, for Peacocke, attributions of genuine content can only be deemed correct given that a thinker is disposed to infer such that those inferential transitions are truth-preserving. But, conceiving of such inferential transitions as required to have thoughts involving a content (and, so also attribution of content to a thinker) would effectively entail routine content-failure. ${ }^{13}$ This seems both implausible and unwarranted, particularly given the significant literature regarding the flexibility regarding mental states that is nonetheless consistent with thinkers having the capacity for attitudes with the relevant content. ${ }^{14}$ It may well be that something other than inferential competency is involved in thinkers grasping content. For example, relevant data from cognitive psychology suggests that that the inferential patterns associated with a logical expression often operate through "quick and dirty" heuristics and associations, where thinkers may rely upon a variety of psychological phenomena such as preferences, emotions, desires and so on. ${ }^{15}$ Routine failures to infer according to a set of natural deduction rules does not provide good evidence for contentfailure, in which case, as we saw above, the semantic content of logical expressions is not settled by the inferential rules thinkers are disposed to make.

\footnotetext{
${ }^{13}$ Similar problems occur for Peacocke's (2004) qualifications that it may be a fundamental "rule of reference" that determines content, since, there the constraints on grasping content are even more substantive than those discussed here.

${ }^{14}$ For an overview, see Medin et. al. (2005).

${ }^{15}$ See Sloman (1996).
} 


\section{Appealing to external factors}

Perhaps Peacocke might attempt to circumvent these issues by appealing to externalism. The idea being: as Putnam (1975) grasps the content of "elm" whilst having the ability to discriminate between elms and beeches, thinkers can have a partial or incomplete grasp of the content of logical expressions. Those thinkers may not be able to understand always which inferences are valid; they would commit fallacies, and so on, but they would still be attributed attitudes to propositions containing the relevant concepts. ${ }^{16}$

Even if this story can be made to work, I do not think that it will help Peacocke. One reason for this has been forcefully advanced by Williamson $(2003 ; 2007)$. I do not wish to belabour the point here as it has been much discussed in the relevant literature, but, in outline it is as follows. Williamson points to Vann McGee's (1985) supposed counterexample to modus ponens, with the suggestion that modus ponens is not, therefore, a valid rule of inference. Williamson goes on to say that (supposing McGee is incorrect), it would still not be the case that we should say that McGee does not grasp the content of modus ponens. Generalising further, the suggestion is this; given that there are philosophical experts that deny that basic inference forms are valid, it cannot be the case that for an inference form to be content-determining, any expert-speaker, competent with the relevant expressions, must be disposed to accept it. Hence, externalism will not help as it entails that (Supervenience) is false.

Peacocke (1998) has suggested that a more moderate version of (Supervenience) may be required for certain conceptual contents, involving implicit conceptions rather than simple possession conditions. ${ }^{17}$ In brief, an implicit conception is taken to be a possession condition for a concept that influences and explains our judgments, but is less stringent than possession conditions (as understood in Peacocke 1992b). So, for example, we might not be primitively compelled to accept the possession conditions for "or", as defined by the natural deduction rules for disjunction. Again, for implicit conceptions to do any serious explanatory work, they must be guaranteed to be truth-preserving given that they are involved in determining the content of the relevant concepts. The problem here

\footnotetext{
${ }^{16}$ This is somewhat problematic as outlined here given that externalism in Putnam's example requires causal-historical links to elms, and, we may presume that there are no such links to logical properties. So, perhaps the kind of externalism required is the social externalism of Burge (1986).

${ }^{17}$ It is worth pointing out that implicit conceptions are not supposed to be necessary for basic logical terms such as conjunction.
} 
is therefore quite clear. Peacocke (1998) must end up simply stipulating as an additional premise that the implicit conception of "or" is: (a or b is true iff either a is true or b is true) (46), in order to guarantee that "or" has the content of classical disjunction. Thus, we end up with the problems regarding justification discussed in $\S 3$. Moreover, appealing to implicit conceptions entails a substantive weakening of the account, since possession conditions will no longer play the relevant role in content ascription, nor provide traction on the justification of the conceptual role that is supposed to determine the content of a concept.

\section{Content and normativity}

Let me sum up the preceding. On Peacocke's theory, there is a type-type relationship between grasp of logical content and a particular symboltokening inferential disposition. However, as I have shown, attitudes to propositions involving the content of a logical expression can be realized by varied symbol-tokening inferential abilities. But, if it is possible for attitudes to propositions involving a concept to be realized by very different symbol-tokening dispositions, then it cannot be a type-type relationship that makes thinkers with varying inferential abilities all realize the state of having an attitude with that concept. So, for example, the semantic content of "true" comes apart from what is required for possession of the concept, and normativity cannot be built into concept possession in so far as this would involve thinkers having false normative commitments.

There are a number of options that we might consider in response. One alternative would be to suggest, as Williamson (2007: 4), that any account that makes certain "acceptance conditions" a necessary condition for content ascription will fail, arguing that there are no inferential constraints on concept possession. He concludes that we should reject the traditional connection between content and rationality. But, this conclusion seems unnecessarily strong, and I agree with Wikforss (2010), that severing the link altogether makes it increasingly problematic to provide a satisfactory account of semantic competence. In answer to Williamson's criticisms, we might also argue that, just because the connections are not transparent does not suffice to show that they do not exist, particularly given that rationality itself appears to involve (perhaps constitutively) consciously understanding the content of the involved terms, as Bill Brewer (1995) observes:

Epistemologically productive reasoning is not a merely mechanical manipulation of belief, but a compulsion in thought by reason, and as such involves some conscious understanding of why one is right in one's conclusions. 
What drives one in genuine cases is precisely what one lacks if one has simply been drilled by the dictators of the International Academy of Logic $[\ldots]$ to reason in ways for which one sees no evident rationale, no point or purpose. $(242-3)$

Given this, I think it is profitable to pursue an alternative position, which allows that we can hold mistaken views regarding the meanings of our terms, since, effectively (Supervenience) is false, given the reasoning in $\S 4$ and $\S 5$. Nonetheless, Peacocke's constraint on the determination of meaning (TP) may be retained so long as explaining thinkers' grasp of logical content is distinguished from explaining thinkers' knowledge of the propositions expressed. This, would, in effect, separate out the two issues defined at the outset of the paper.

On this view, we might adopt a more liberal, Davidsonian (2001: 221-3), approach to concept possession requiring a norm of rationality such that for a thinker to have attitudes, those attitudes must be, on the whole, rational, suitably cohere with one another, and so on. But, this may be combined with the idea that logic is concerned with necessary truth-preservation across argument, which is dependent upon the content of the propositions involved. As pointed out above, in order that a thinker correctly uses a sentence involving a logical term, that thinker must also be justified in believing, of the proposition expressed by that use, that it is truth-preserving. Peacocke's theory of meaning is supposed to provide this sort of justification for (TP), but it fails, since, as in the case of "true", this may require far further reflective, and even theoretical, activity.

There is some support for this kind of account from cognitive psychology. As discussed in $\S 4$, ordinary concept possession involves a variety of abilities and associations; involving dispositions, desires, preferences, emotions relying on perceptual similarity, stereotypes, and temporal regularity (Medin et. al. 2005). So, having propositional attitudes requires no specific underlying psychological behavior to be implemented in the form of inferential dispositions and practices.

However, our capacity for rational inference is not delimited by ordinary heuristic inferential abilities. It is possible for thinkers to come to have an improved understanding of concepts in tandem with a greater ability to exercise the inferences and judgments corresponding certain norms of inference. ${ }^{18}$ For example, Kahneman and Tversky (1982) showed that many participants, having committed the conjunction fallacy, were willing to defer to the classical rules, admit to making a mistake and revise their

\footnotetext{
${ }^{18}$ In the literature, these are usually assumed to coincide with classical logical inferences, but there appears little support for this assumption given the burgeoning literature on non-classical logic; see Priest (2001) for a survey.
} 
judgments accordingly. In addition, Agnoli and Krantz (1989) also found that (prior) brief training in the logic of sets (using Euler circles) markedly improved the performance of participants.

One explanation for this, for which there is much evidence for, is the "dual-process" theory of reasoning (Sloman 1996; West \& Stanovich 2000). Such theories suggest that there are two systems of human reasoning: System-1 processes, which are automatic, associative, and heuristic based; and, System-2 processes, which are controlled, deliberate, serialized and general. Typically, Type-2 processes are taken to be responsive to rational norms such that they decontextualise the rules involved in inference and judgment. The heuristic associations primed in the Linda problem, for example, result from System-1 processes, which can be overridden by higher-level cognitive functions generated by Type-2 reasoning. ${ }^{19}$

On this story, we have a basic, empirically tractable account of concept possession, that suggests that thinkers routinely display a tendency to attempt to systematise heuristic inferential practices towards improving their performance, in line with a tendency to reason according to certain evaluative norms. It is the project of epistemological and logical theories to determine what these evaluative norms are, such that they conform to the norms of rationality. But, whatever the epistemic norms are, they do not appear at the level of basic dispositions. ${ }^{20}$

\section{References}

Agnoli, F., \& D. H. Krantz 1989. "Suppressing natural heuristics by formal instruction: The case of the conjunction fallacy", Cognitive Psychology 21, 515-550.

Belnap, N. D. 1962. "Tonk, plonk and plink”, Analysis 22, 130-34.

Boghossian, P. A. 2001. "Inference and insight", Philosophy and Phenomenological Research 63, 633-640.

BonJour, L. 1985. The Structure of Empirical Knowledge (Cambridge, MA: Harvard University Press).

Brewer, B. 1995. "Mental causation: Compulsion by reason", Aristotelian Society Supplementary Volume 69, 237-253.

Burge, T. 1986. "Individualism and Psychology", The Philosophical Review 95, 3-45.

\footnotetext{
${ }^{19}$ See West \& Stanovich (2000: 659).

${ }^{20}$ Earlier versions of this paper were presented at a seminar at CSMN Oslo and ESPP 2013. Special thanks for helpful comments to the audiences, and particularly Alex Tillas and Georg Kjoll.
} 
Chomsky, N. 1965. Aspects of the Theory of Syntax (Cambridge, MA: MIT Press).

Davidson, D. 2001. Inquiries into Truth and Interpretation (2nd ed.) (Oxford: Oxford University Press).

Dummett, M. 1973. Frege: Philosophy of Language (London: Duckworth).

Eklund, M. 2002. "Deep inconsistency”, Australasian Journal of Philosophy 80, 321-331.

Harman, G. 1986. Change in View: Principles of Reasoning (Cambridge, MA: The MIT Press).

Horwich, P. 2005. Reflections on Meaning (Oxford: Oxford University Press).

Kahneman, A. \& D. Tversky. 1982. Judgment Under Uncertainty: Heuristics and Biases (Cambridge: Cambridge University Press).

Kalderon, M. E. 2001. "Reasoning and representing”, Philosophical Studies 105, 129-60.

Kripke, S. 1975. "Outline of a theory of truth”, Journal of Philosophy 72, 690-716.

—. 1982. Wittgenstein on Rules and Private Language (Cambridge, MA: Harvard University Press).

Lewis, D. 1997. "Finkish Dispositions”, The Philosophical Quarterly 47, 143-158.

McGee, V. 1985. "A counterexample to modus ponens", Journal of Philosophy 82, 462-471.

Medin, D.L., B. Ross, A. Markman. 2005. Cognitive Psychology (4th ed.) (New York: John Wiley and Sons).

Peacocke, C. 1987. "Understanding logical constants: A realists account", Proceedings of the British Academy 73, 153-200.

_. 1992a. "Sense and Justification", Mind 101, 793-816.

—. 1992b. A Study of Concepts (Cambridge, MA: MIT Press).

_. 1998. "Implicit conceptions, understanding and rationality", Philosophical Issues 9, 43-88.

1999. Being Known (Oxford: Clarendon,).

- 2004. The Realm of Reason (Oxford: Oxford University Press).

—. 2005. "Justification, realism and the past", Mind 114, 639-670.

Priest, G. 2001. An Introduction to Non-Classical Logic (Cambridge: Cambridge University Press).

Prior, A. N. 1961. "The runabout inference ticket", Analysis 21, 38-9.

Putnam, H. 1975. "The meaning of 'meaning”". In K. Gunderson (ed.), Language, Mind, and Knowledge (Minneapolis: University of Minnesota Press). 
Schechter, J. and D. Enoch. 2006. "Meaning and justification: The case of modus ponens", Nous 404, 687-715.

Sloman, S. A. 1996. "The empirical case for two systems of reasoning", Psychological Bulletin 119, 3-22.

West, R., K. Stanovich. 2000. "Individual differences in reasoning: Implications for the rationality debate?" Behavioral and Brain Sciences 23, 645-665.

Wikforss, A. 2010. "Are there understanding-assent links?" The Baltic International Yearbook of Cognition, Logic and Communication 5, 1-17.

Williamson, T. 2003. "Understanding and inference”, Aristotelian Society, Supplementary Volume 77, 249-93.

_ 2007. The Philosophy of Philosophy (Malden, MA: Blackwell). 